\title{
بداية مسؤولية الناقل البحري عن البضاعة التي تسلمها في القانون الجزائري والاتفاقيات الدولية
}

\author{
د.بودليو سليم \\ كلية الحقوق \\ جامعة الإخوة منتوري قسنطينة

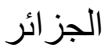

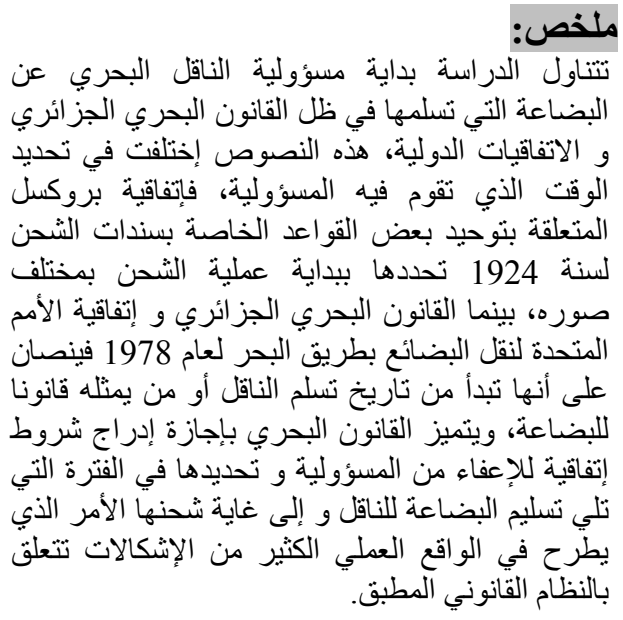

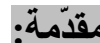

بعتبّر تسلم البضاعة في النقل البحري

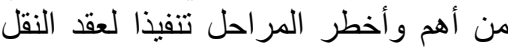

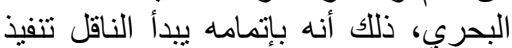

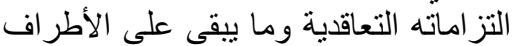

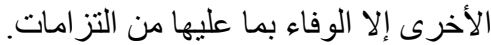

غير أن التشريعات الوطنية والواءئ والاتفاقيات

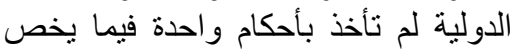

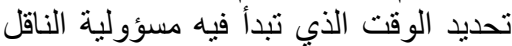

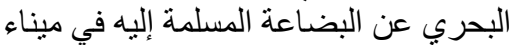

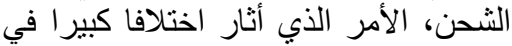

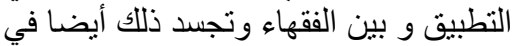

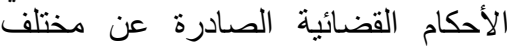

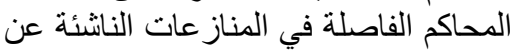

هذه المسؤولية.

\section{Abstract:}

This study deals with the beginning of the sea carrier liability for the goods received by the light of the algerian maritime law and international conventions, these texts differed in determining the time when the responsibility, the convention on Brussels for the unification of certain rules for bills of lading for the year 1924 determined by the beginning of the brocess of charging various forms, while maritime law algeria and the united nations convention on the carriage of goods by sea 1978 , vinsan as starting from the date of receipt by the carrier or his authorized representative of the goods, and is characterized by maritime law leave the inclusion of the therms of an agreement for an exemptoin from responsibility and identified in the period after delivery of the goods to the carrier and up to which shipped put in practice a lot of problems related to the legal regime applicable . 


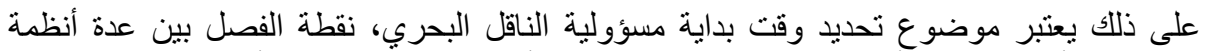

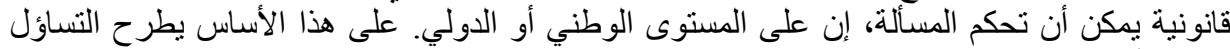

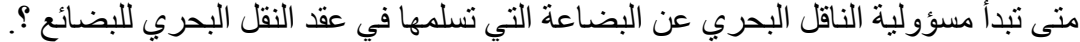

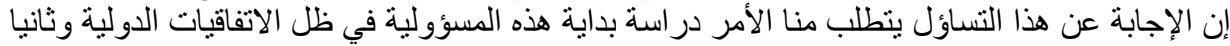

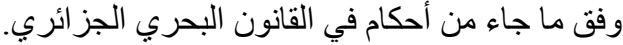

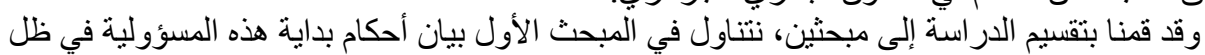

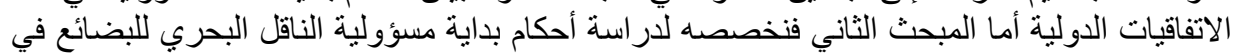

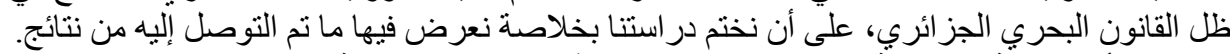

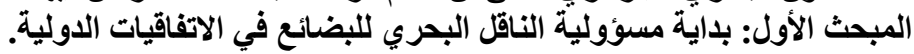

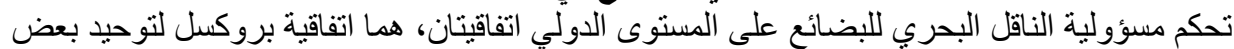

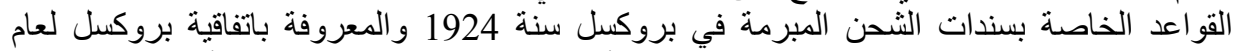

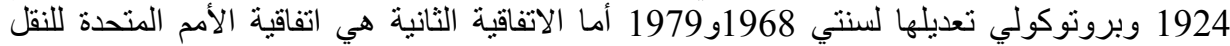

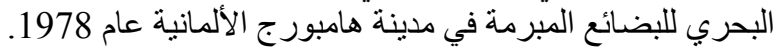

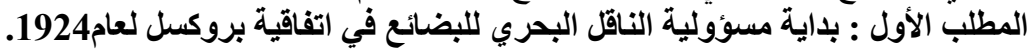

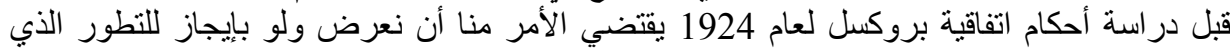

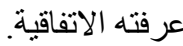

أولا: التطورات التي أدت إلى وجود الاتفاقية و التعديلات التي أدخلت عليها(1).

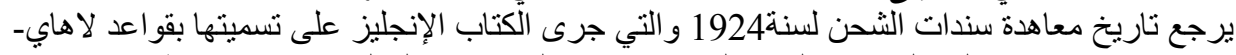

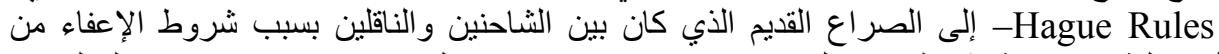

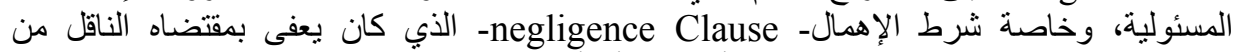

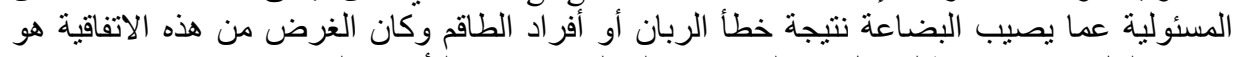

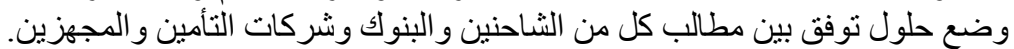

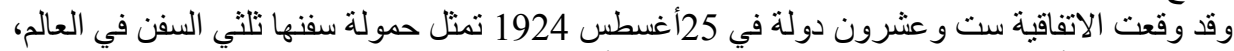

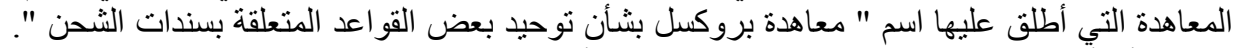

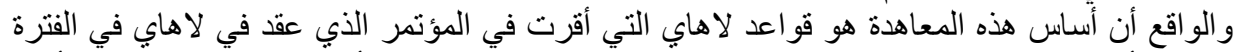

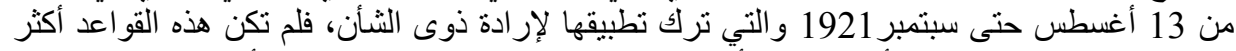

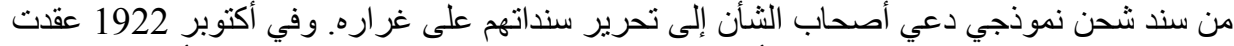

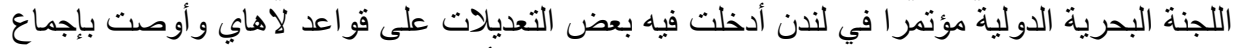

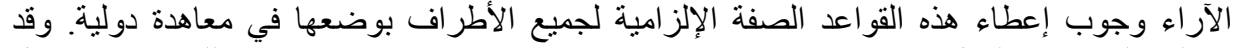

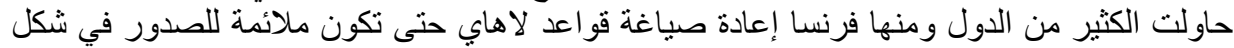

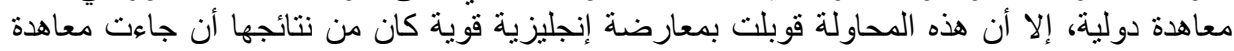

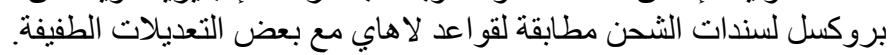

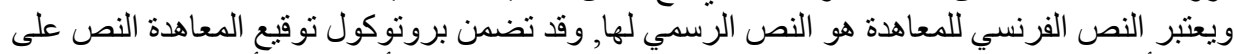

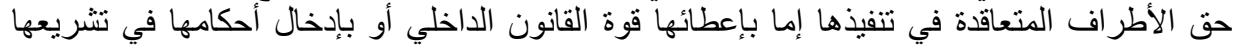

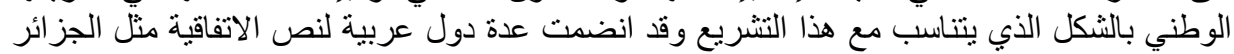

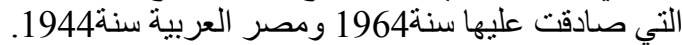

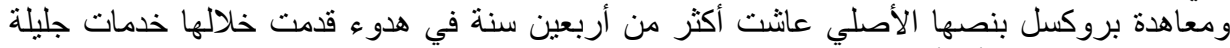

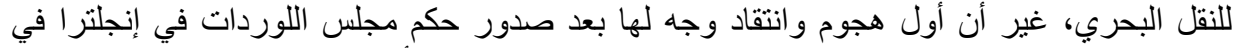

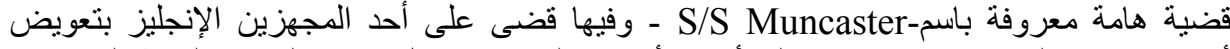

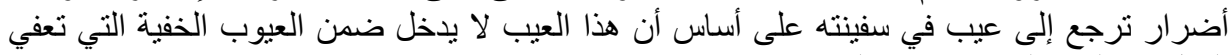
الناقل من المسئولية في مفهوم المعاهدة. 


\section{باية مسؤولية الناقل البحري عن البضاعة التي تسلمها \\ في القانون الجزائري والاتفاقيات الدولية الإية}

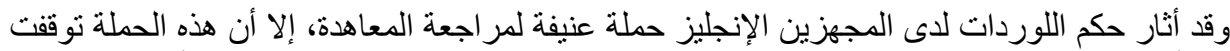

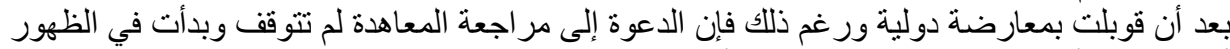

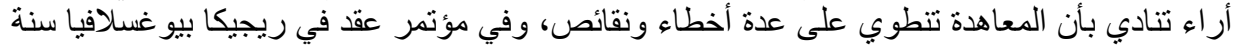

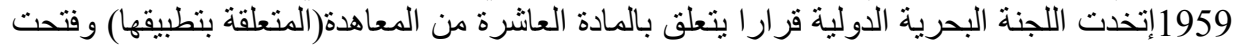

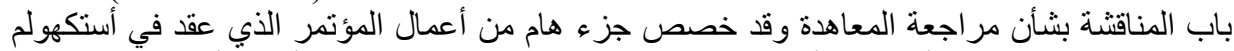

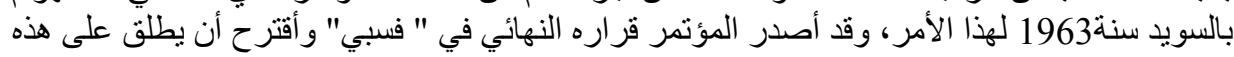

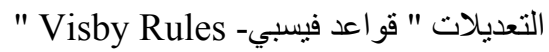
ور غم المعارضة التي واجهتها هذه القو اعد من طرف على عدد من الدول فإن المؤتمر الدبلوماسي الذي عقد

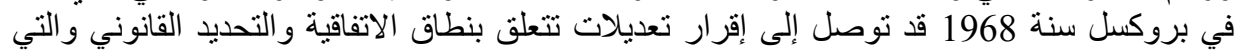

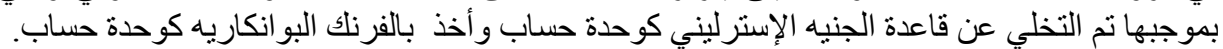

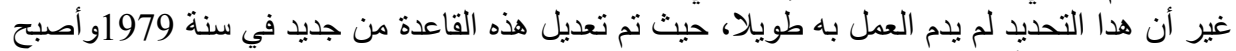

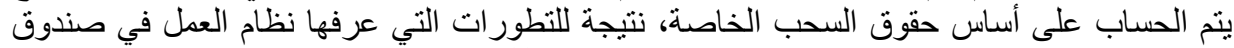

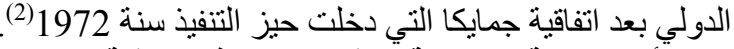

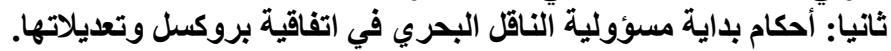

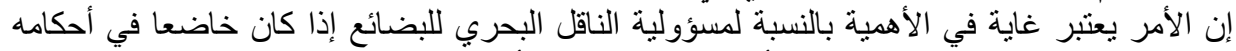

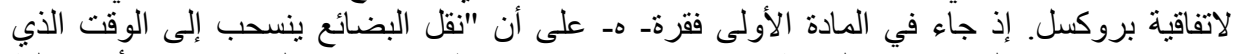

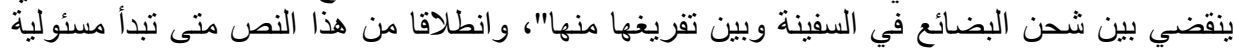

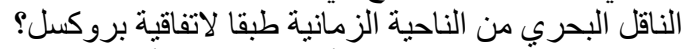

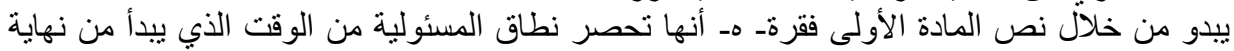

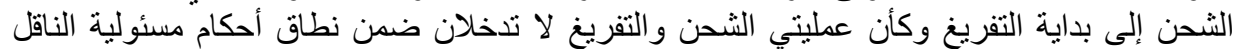

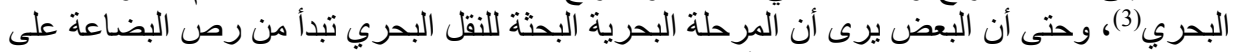

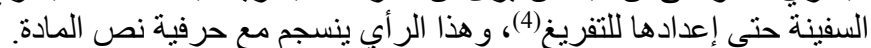

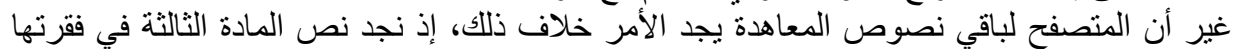

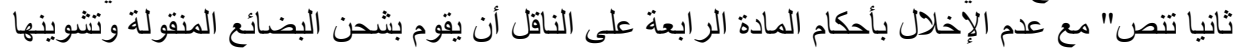

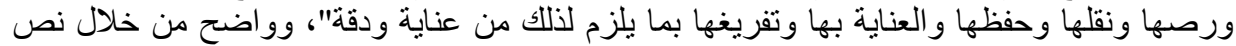

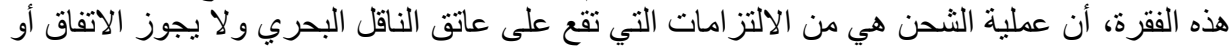

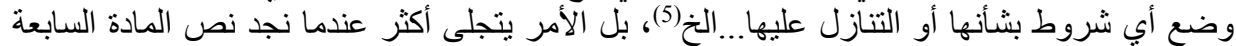

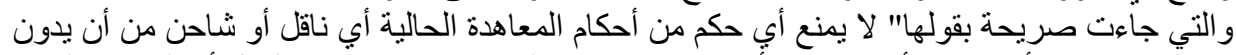

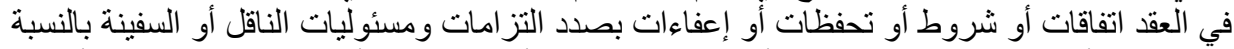

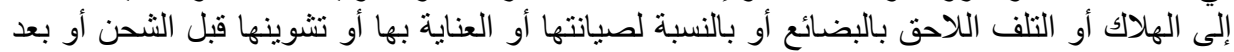

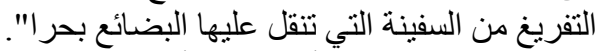
بمعنى انه يجوز إدر اج أي شروط عأو الففاقات عن المرحلة السابقة على الثحن و اللاحقة للتفريغ وبمفهوم

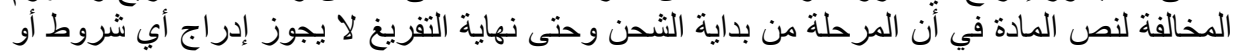

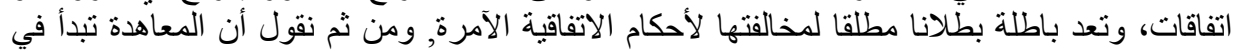

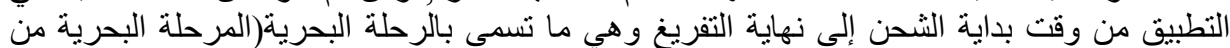

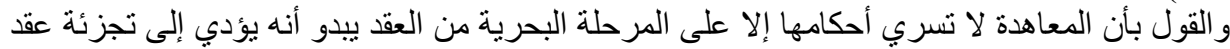

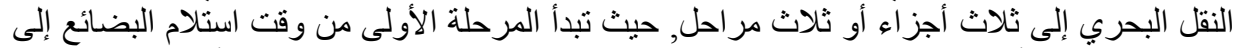

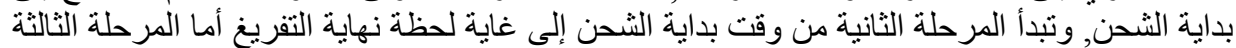

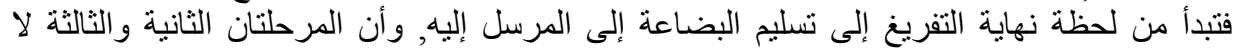

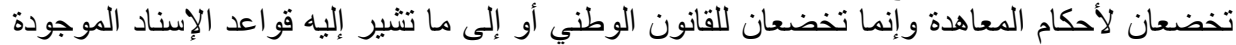

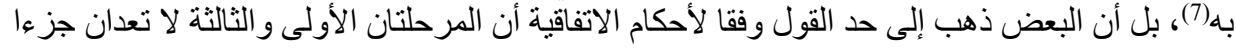


من عقد النقل البحري, طالما أنه يجوز لأطراف العقد إدراج أية شروط أو تحفظات أو اتفاقات في

إنه رغم تجزئة العقد إلى ثلاثة مر احل، إلا أن مبدأ وحدة عقد النقل البحري لا يزال ساري المفعول,

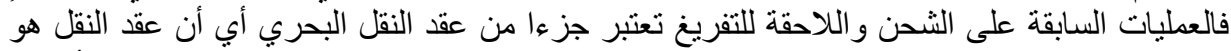

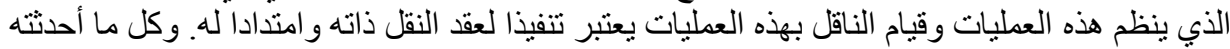

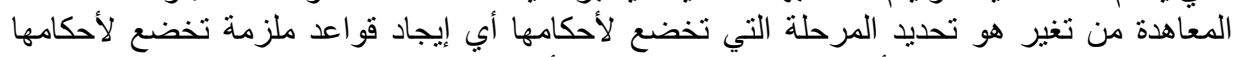

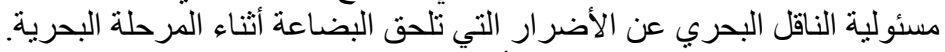

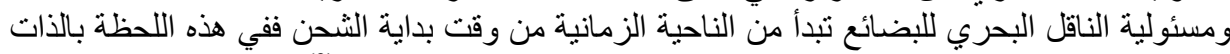

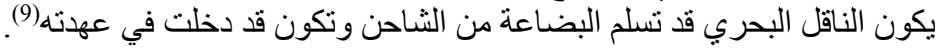

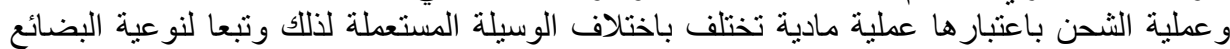

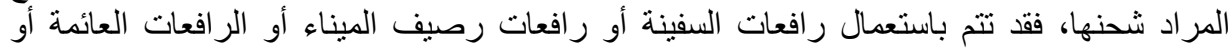

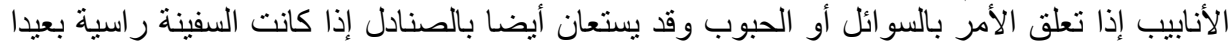

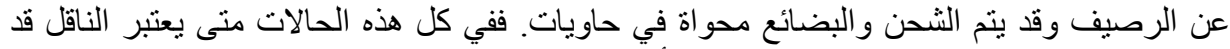

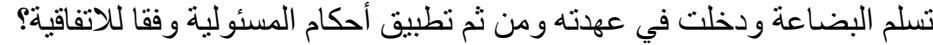
بالنسبة للوضع العادي وهو الثحن عن طريق الروافع فإن الأمر يختلف حسب ما إذا كانت التهان الرو افع تابعة لإلسفينة أو تابعة للميناء.

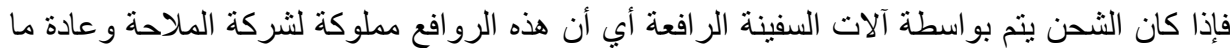

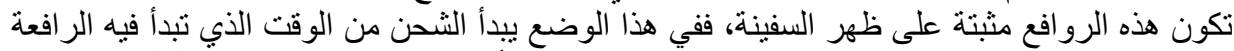

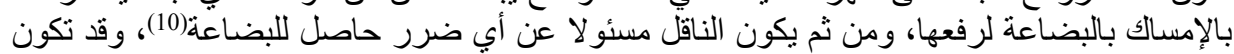

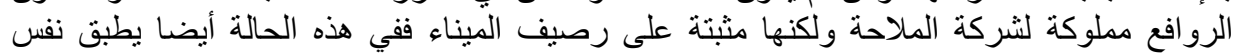

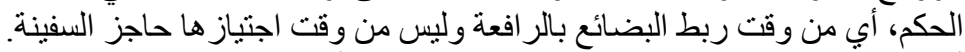

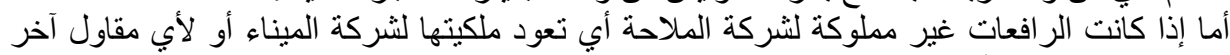

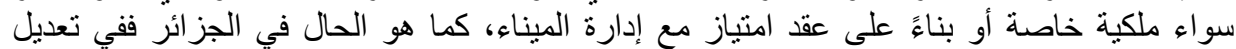

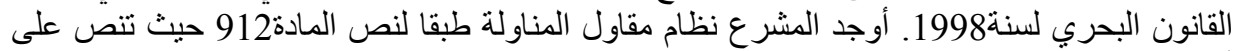

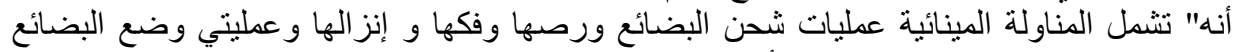

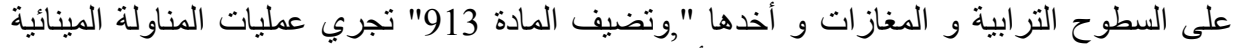

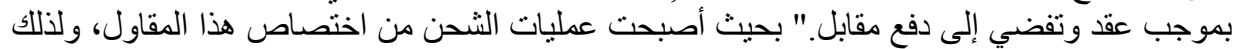

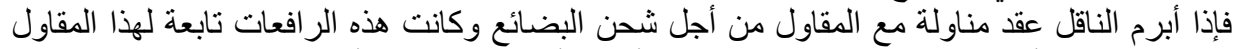

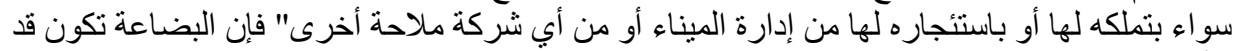

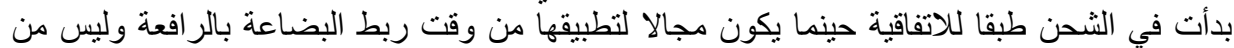

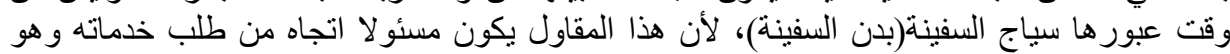

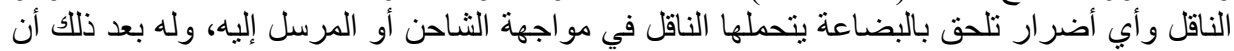

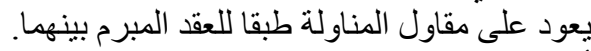

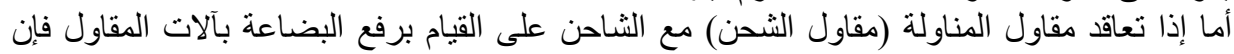

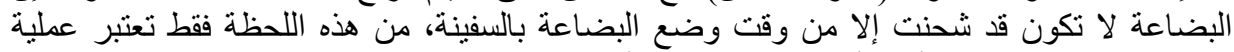

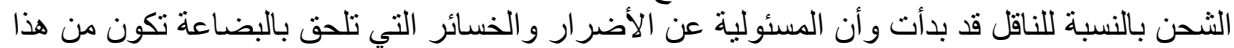

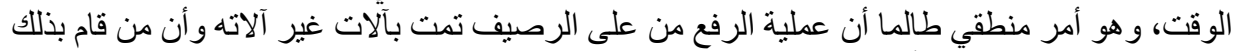

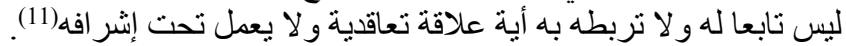

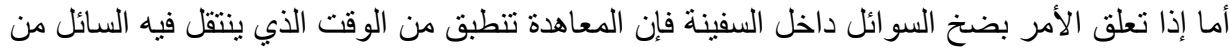

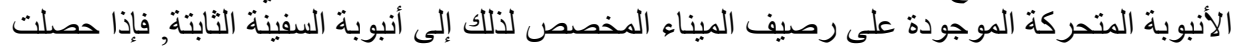

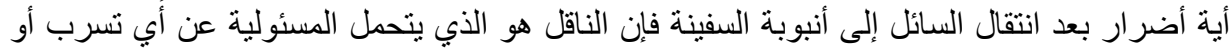
نقص ناتج عن ذلك. 


\section{باية مسؤولية الناقل البحري عن البضاعة التي تسلمها

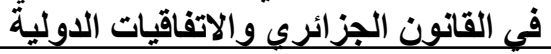

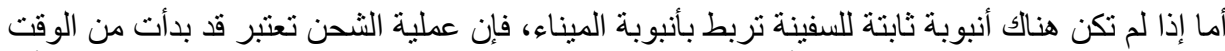

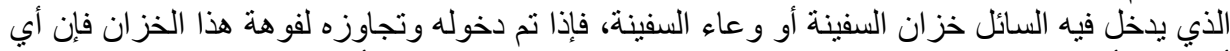

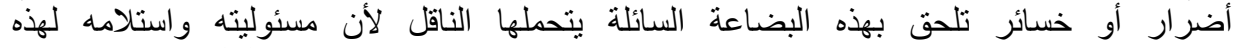

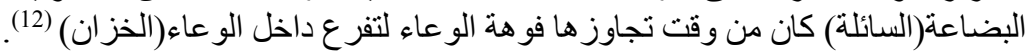

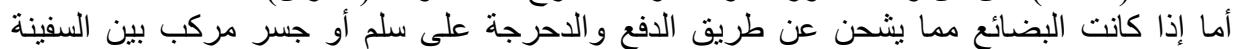

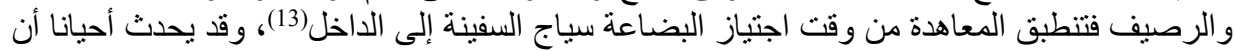

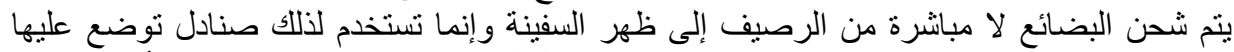

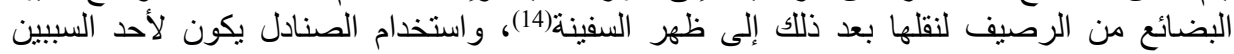

الأول: يتعلق بالسفينة و الناقل وذلك يكون في حالة الثحن و التفريغ بو اسطة استخدام الصنادل في الأماكن

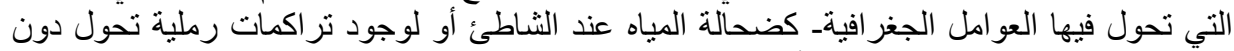

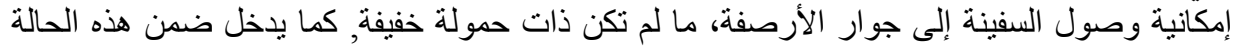

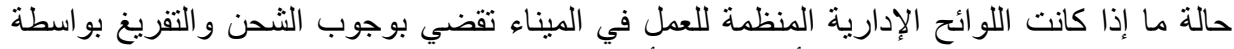

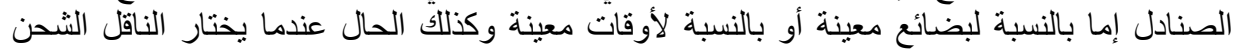

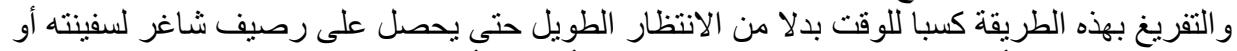
تفاديا لدفع رسوم أكثر إن تم الثحن والتفريخ التفريغ عند الأرصفة أو ليتخلص من رسوم الإرشاد داخل الميناء...الخ (15).

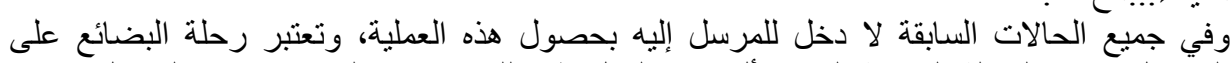

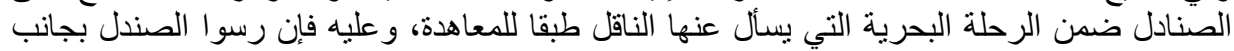
الرصيف للثحن وكأنه السفينة تطبق عليه القو اعد الخاصة بالسفينة و رسو ها بجانب الرئن الرصيف السابق

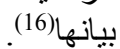
بمعنى آخر إذا لم يكن الثاحن هو الملزم بالنقل على الصنادل بموجب اتفاقية الأطر اف(الناقل و الثاحن)

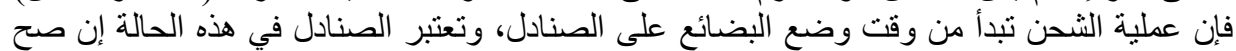

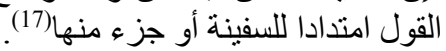

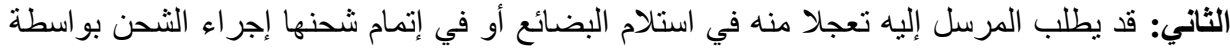

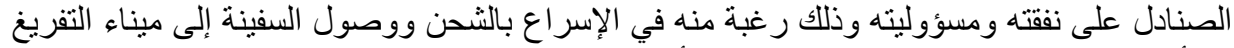

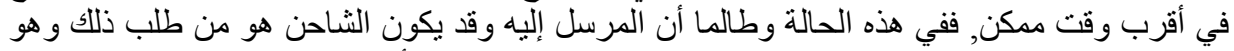

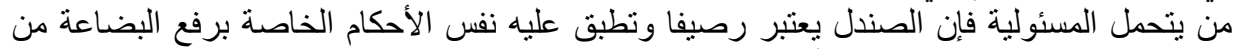
على الرصيف إلى السفينة والمبينة أعلاه (18).

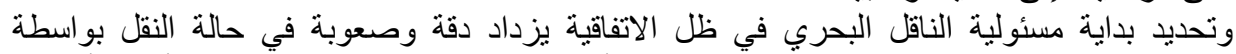

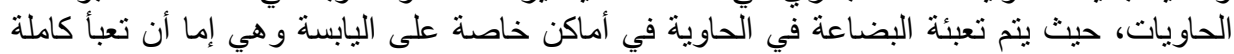

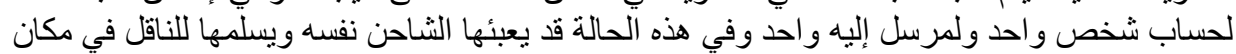

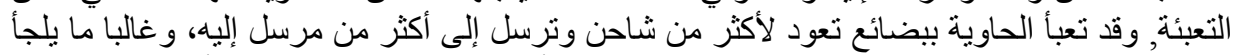

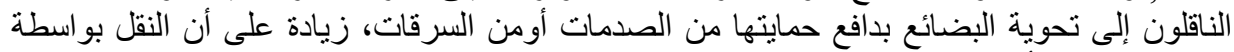

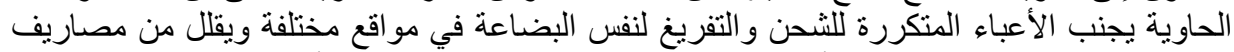

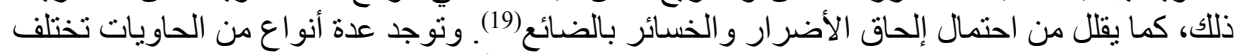

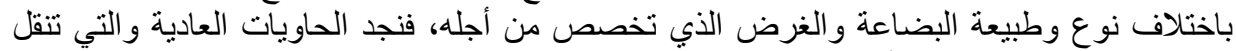

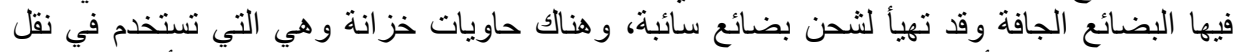

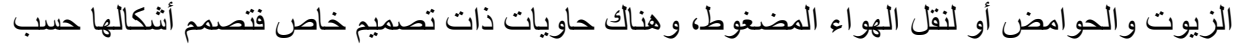

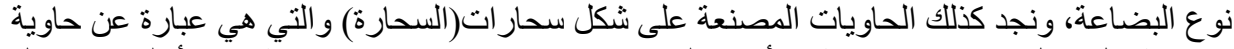

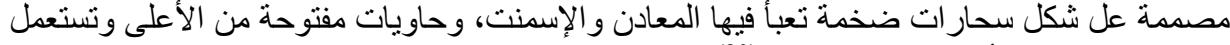
لنقل البضائع النقيلة أو ذات الحجم الكبير (20). 
وبعد تعبئة البضائع في الحاوية يتم غلق الحاوية وختمها ثم تنقل بواسطة الثناحنة أو القطار أو أية

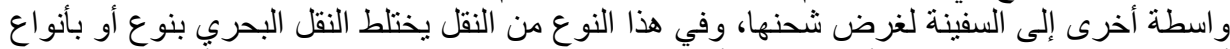

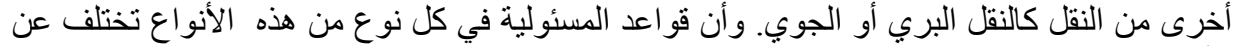

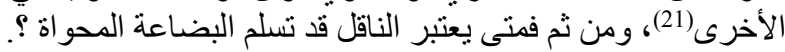

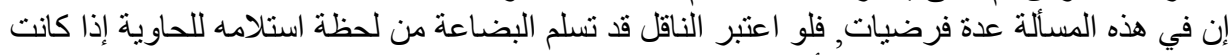

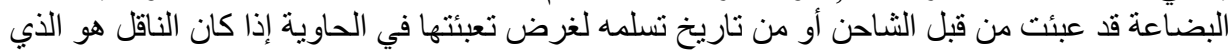

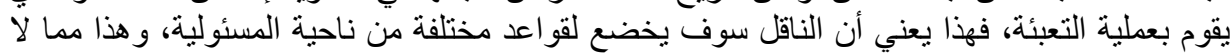

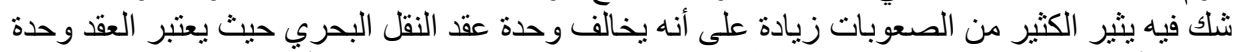

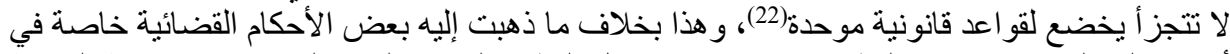

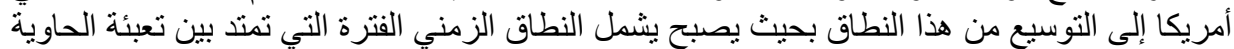

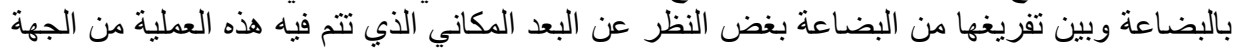

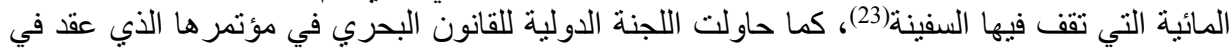

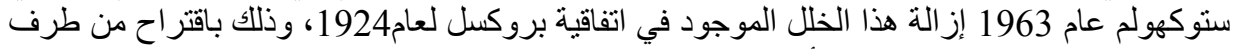

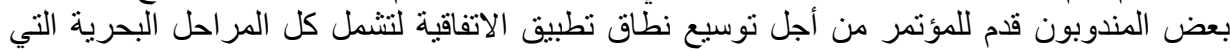

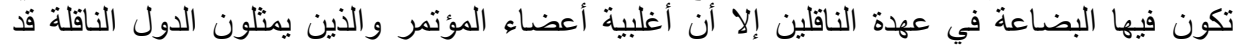

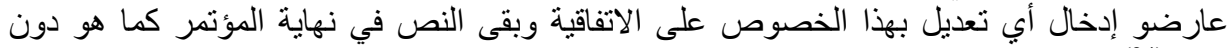
تعديل(24).

أعتقد في هذه المسألة، أنه لا يجوز تحت غطاء التطور في هذا النوع النوع من النقل، التوسيع في نطاق

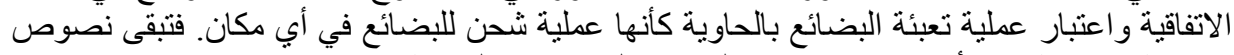

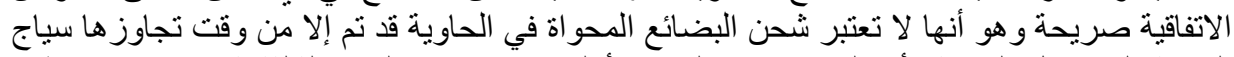

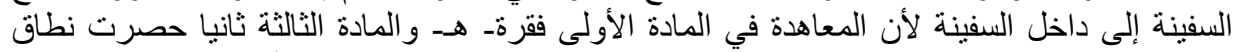

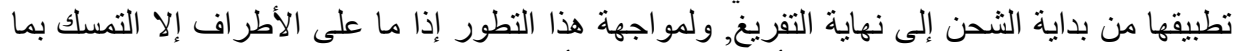

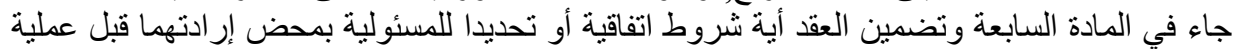

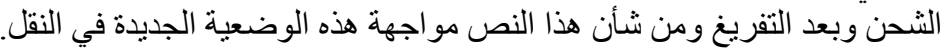
غير أنه في كل العمليات السابقة التي تتم بها عملية الثندن قد يصعب تحديد وقت وقئ وقو ع الضرر, هل قبل

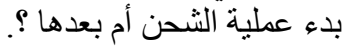
ففي هذه المسألة فإن الفقه قد أجمع فيما يخص اتفاقية بروكسل على افتر اض اضل حدوثه في المرحلة البحرية

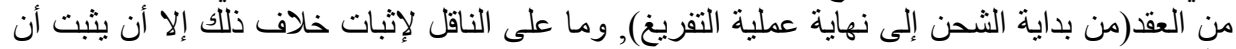

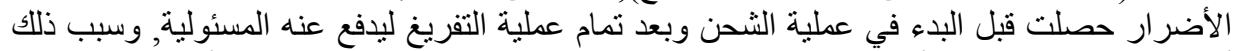

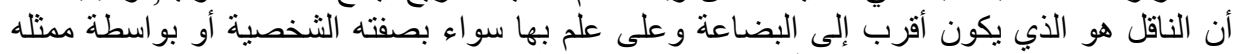

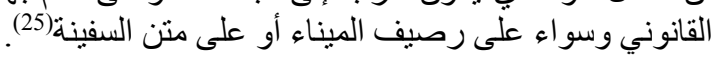

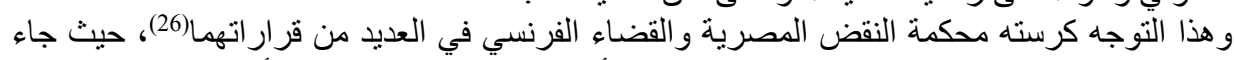

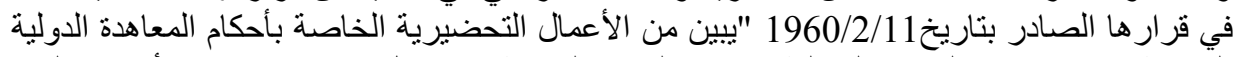

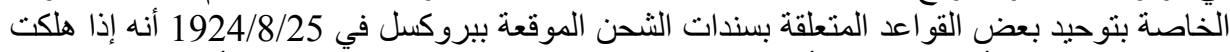

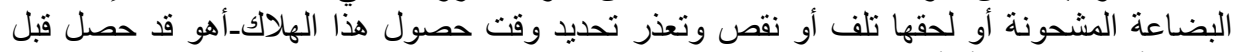

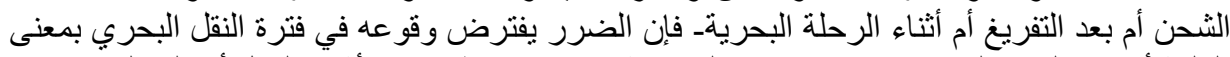

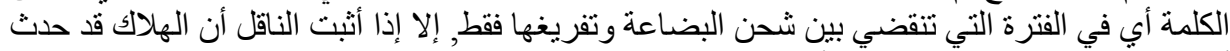

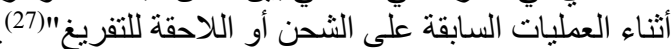

المطلب الثاني: بداية مسؤولية الناقل البحري للبضائع في اتفاقية هامبورج لسنة 1978.

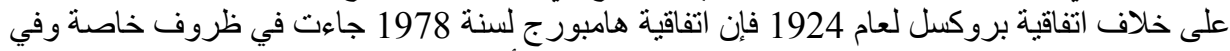
إطار المساهمة الفعالة للاول النامية وفق ما نبينه في الفرع الأول ألفادل من هذا المطلب. 


\section{بداية مسؤولية الناقل البحري عن البضاعة التي تسلمها في القانون الجزائري والبحزي عن الاتفاقيات الدوليةً}

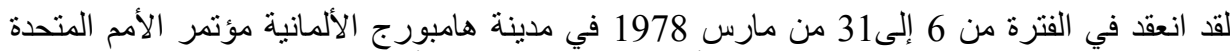

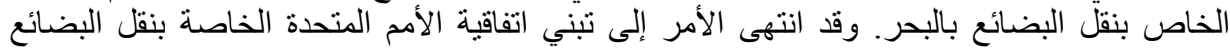

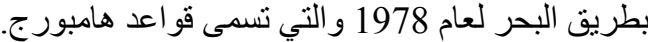

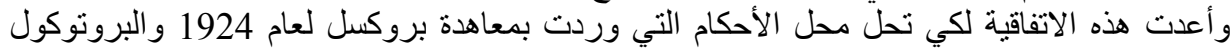

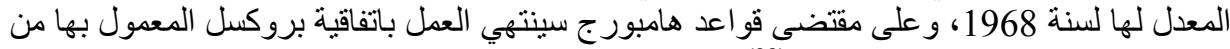

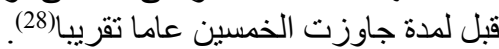

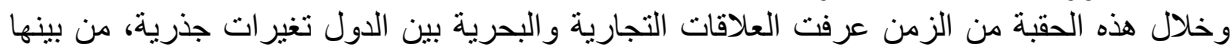

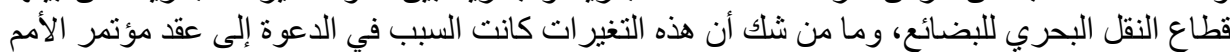

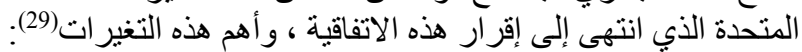

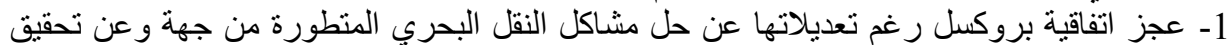

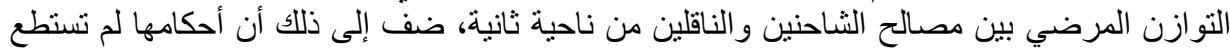

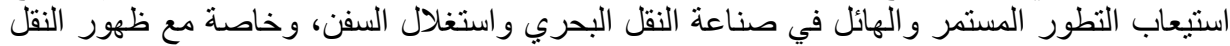

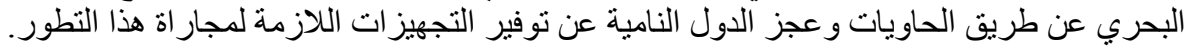

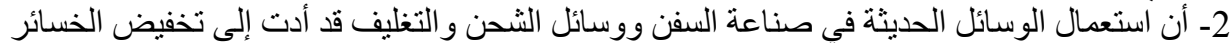

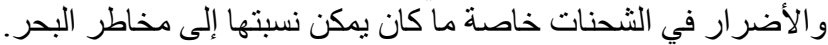

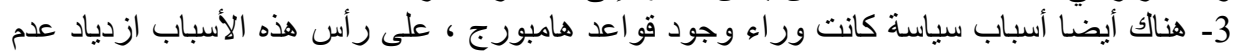

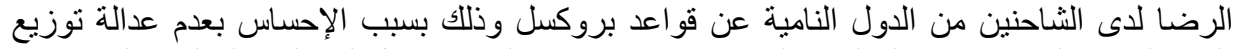

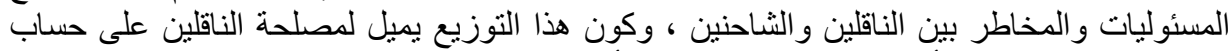

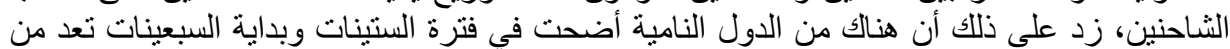
الدول الناقلة كالصين و الهند مثنلا.

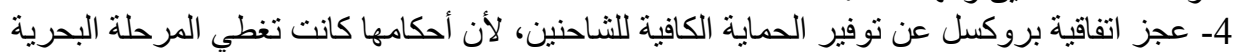

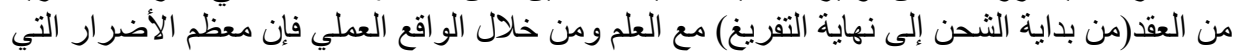

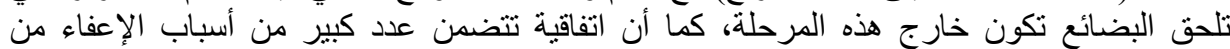

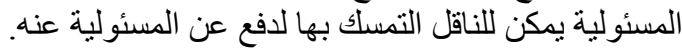

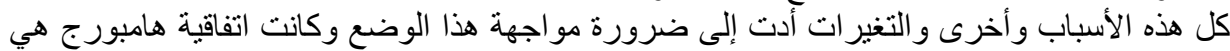

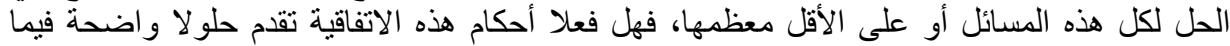

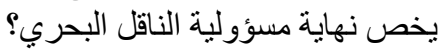

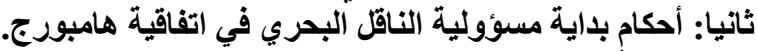

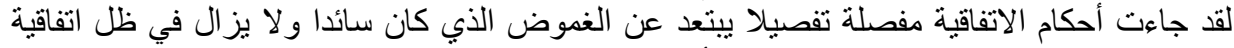

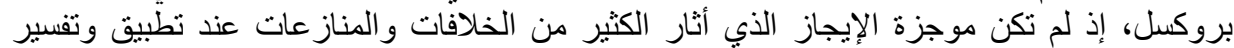

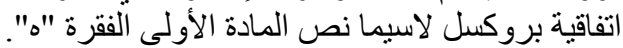

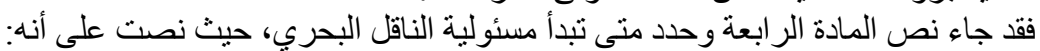

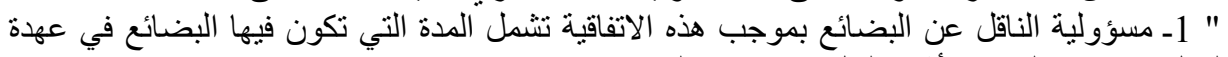

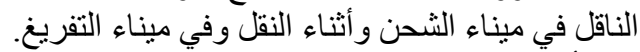

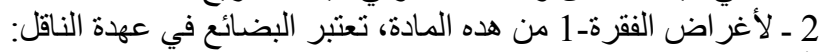
أ ـ اعتبار ا من الوقت الذي يتلقى فيه البضائع:

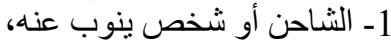

2- سلطة أو طرف ثالث أخر توجب القو انين و اللو ائح السارية في ميناء الثحن تسليم البضائع له لغرض

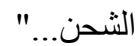

من خلال هذا النص تنضح لنا النتائج أو المسائل التالية:

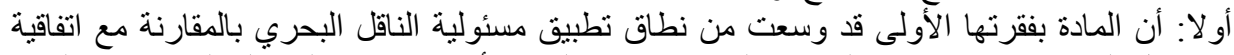

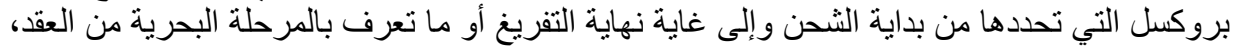




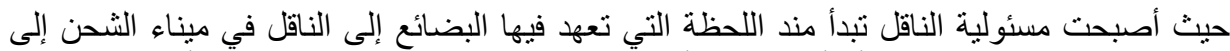

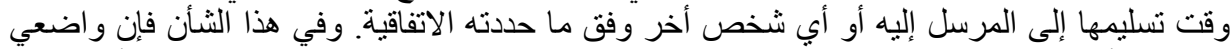

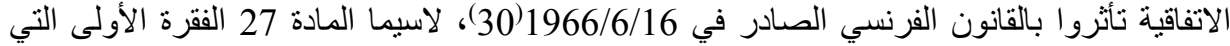

جاء فيها:

" Le transporteur est responsable des pertes ou dommages subis par la marchandise depuis la prise en charge jusqu'à la livraison."

ثانيا: أن مسئولية الناقل البحري عن البضائع وفقا لنص الاتفاقية تبدأ في الأحو ال الآتية:

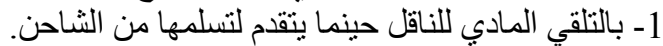

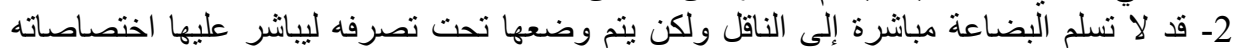

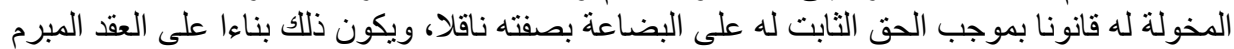

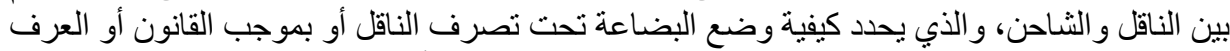

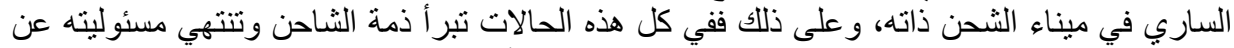

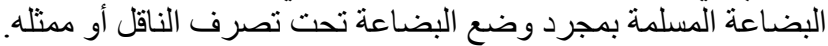

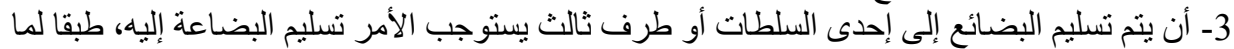

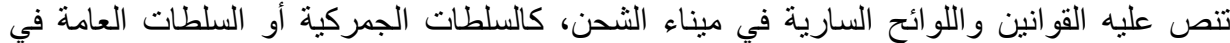

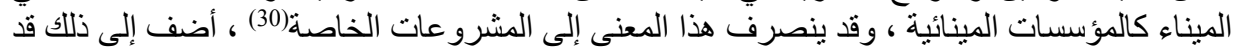

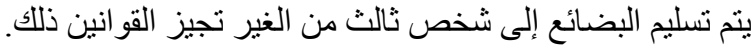

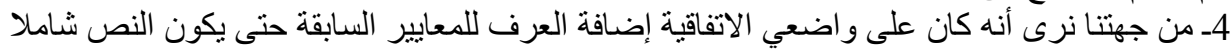
وقابلا للتعامل مع الظروف الحالية و المستقبلية.

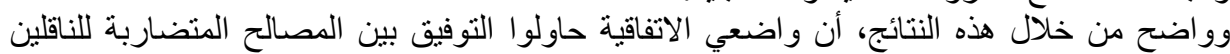

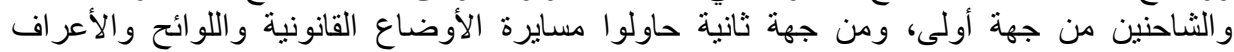

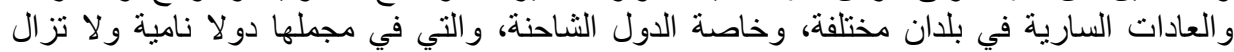

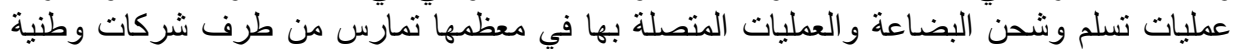

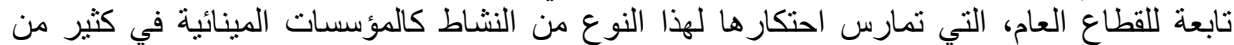

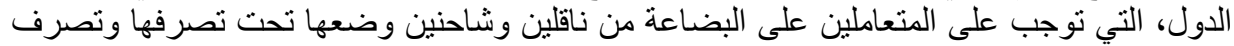

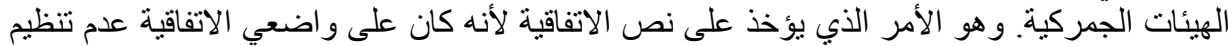

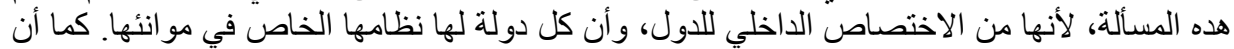

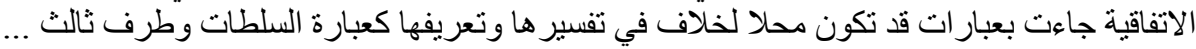

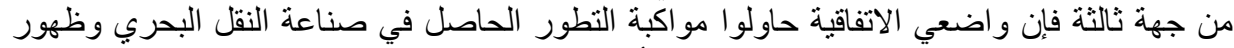

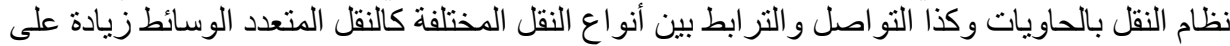

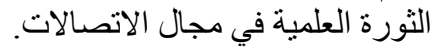
ما يجب قوله أن الاتفاقية وبالر غم مما يقال عنها بأنه فيها نقائص و غموض وضئ وغير ها من الملاحظات إلا

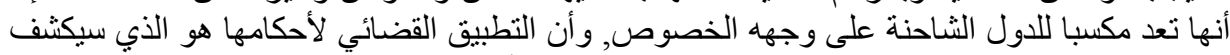

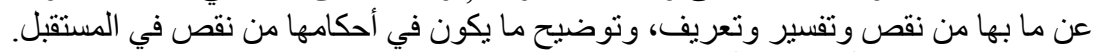

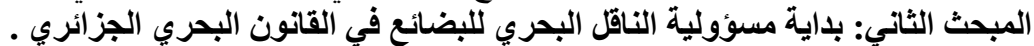

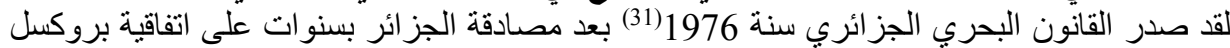

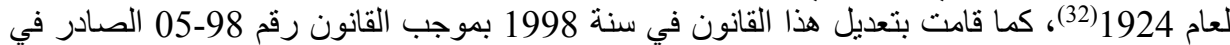
.33) 1998

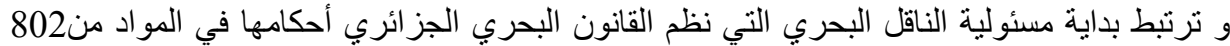

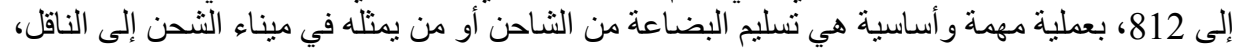

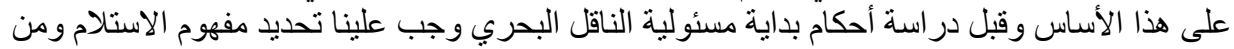

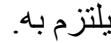




\section{باية مسؤولية الناقل البحري عن البضاعة التي تسلمها في القانون الجزائري والاتفاقيات الدولية}

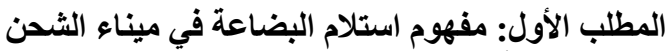

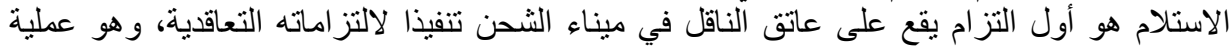

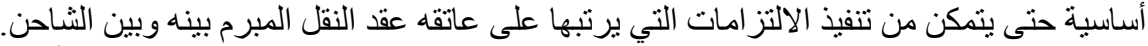

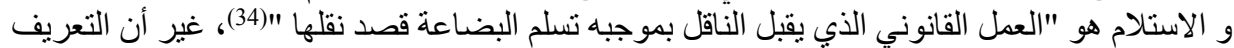

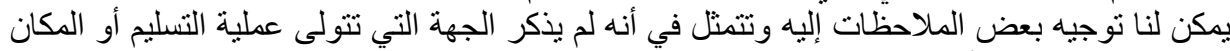

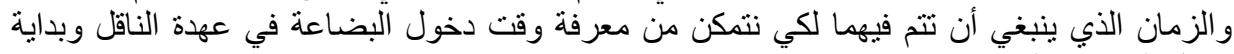

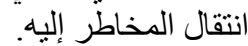

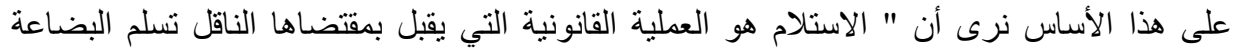

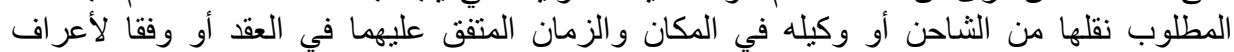

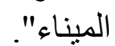

إذا فعملية النقل البحري للبضائع تبدأ باستلام الناقل للبضائع من الثشاحن في المكان و الزمان النان المحددين في

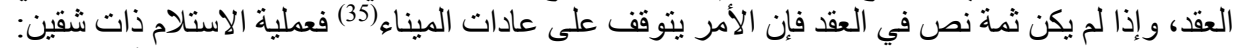

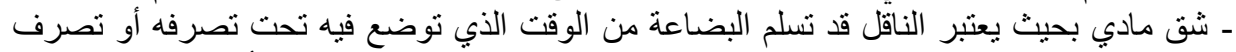

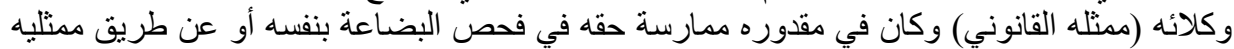

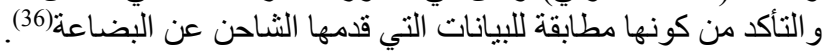

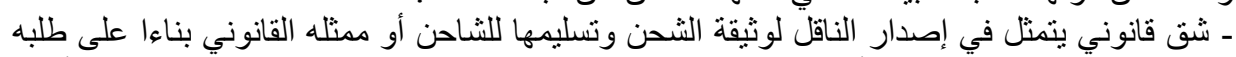

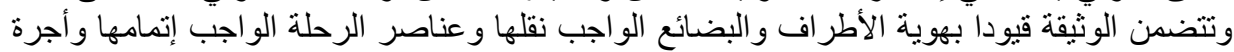

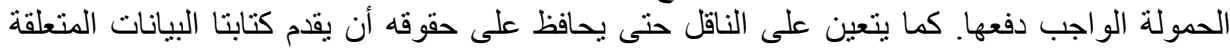

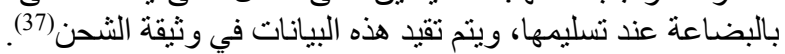

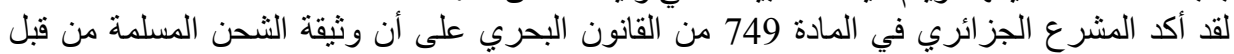

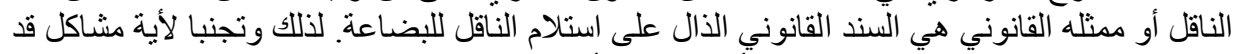

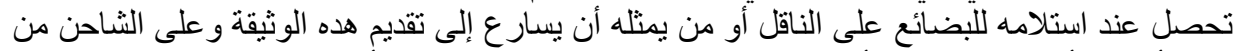

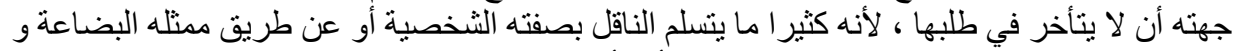

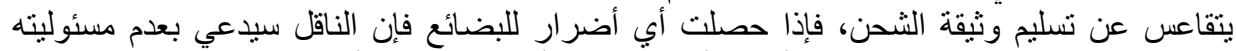

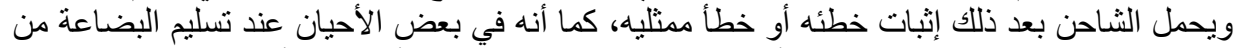

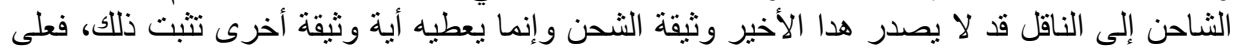

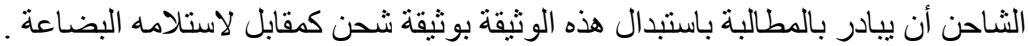

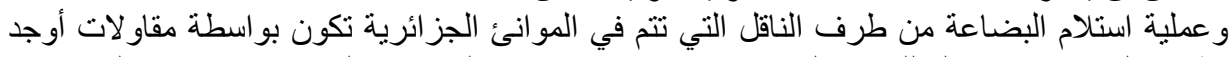

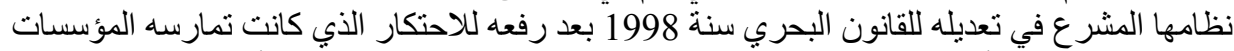

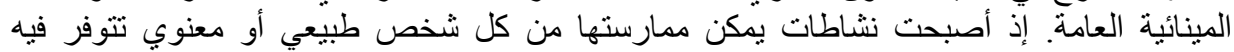

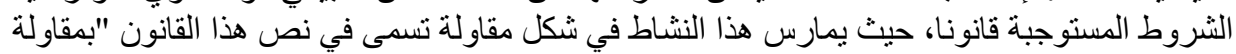

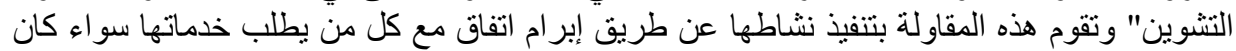

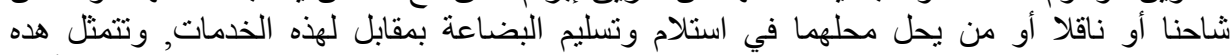

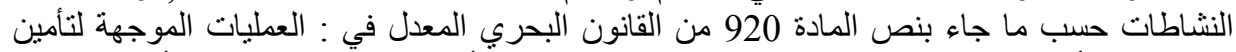

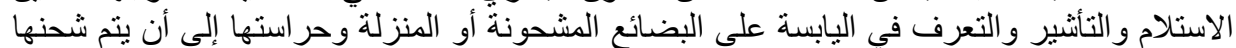

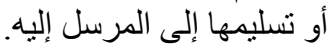

أما من حيث المسئولية فالمقاول مسئول اتجاه من طلب خدماته ووفقا للعقد المبرم معه، فقد نصت المكت المادة

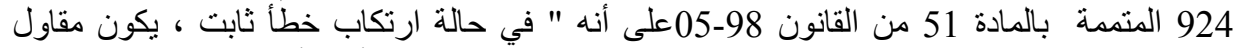

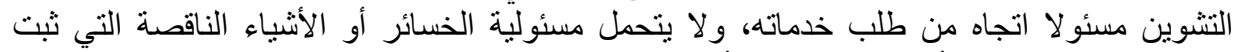

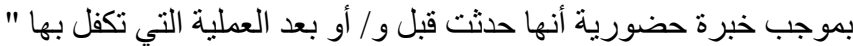

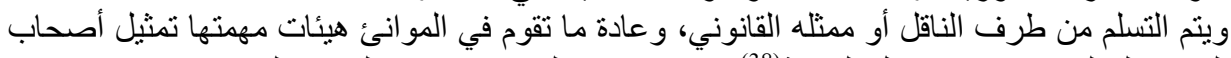

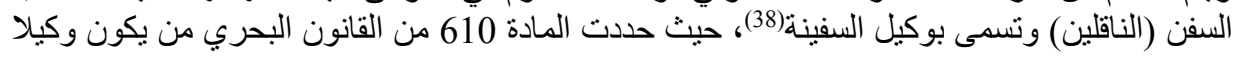




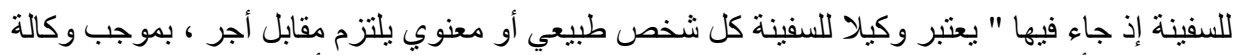

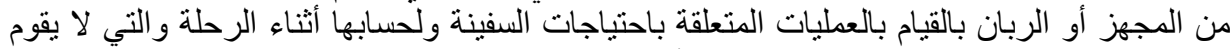

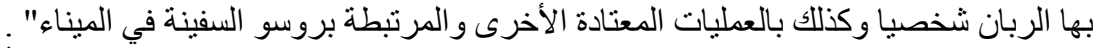

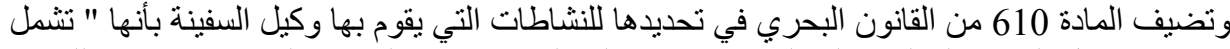

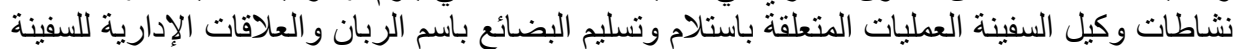

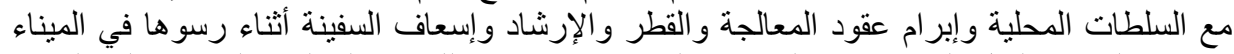

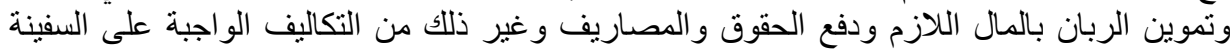

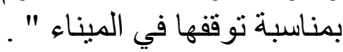

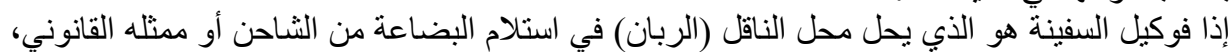

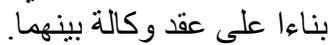

المطلب الثاني: أحكام بداية مسؤولية الناقل البحري

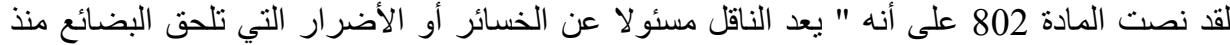

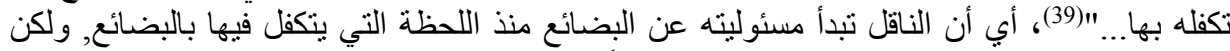

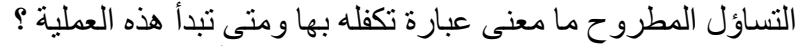

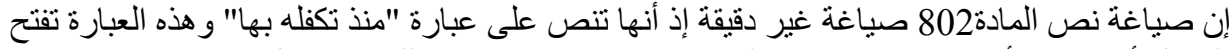

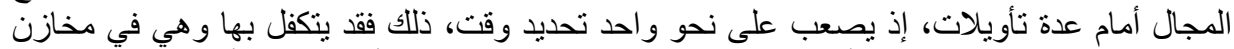

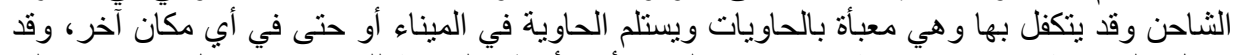

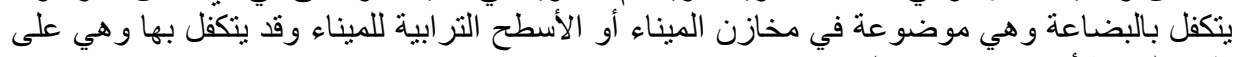
ظهر السفينة أي بعد شُحنهاعـ..الخ.

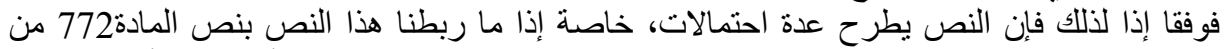

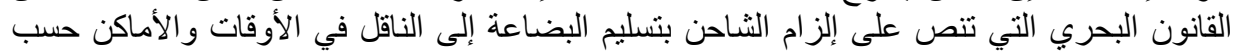

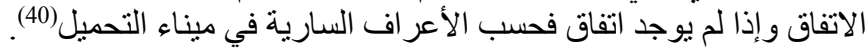

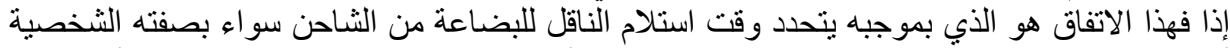

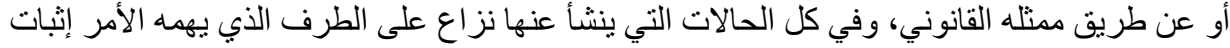

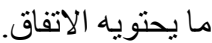
وفقا لهذا النص فإنه يمكن أن يحصل الاتفاق على أن الاستلام يكون بعد شحن البضاعة على ظهر الإنى

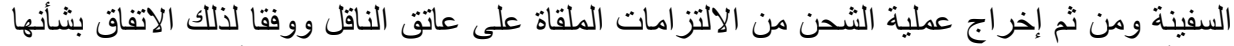

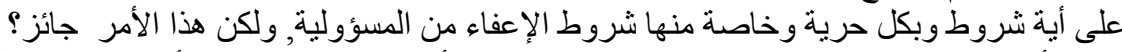

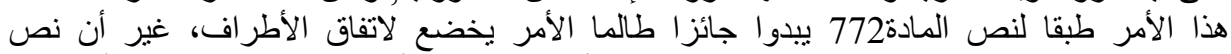

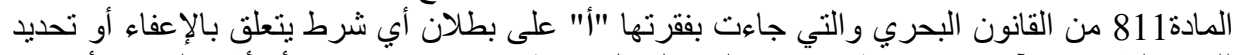

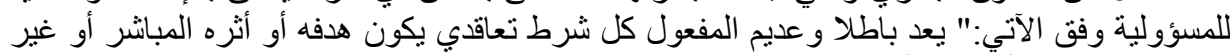

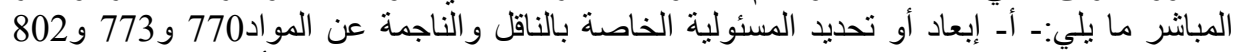

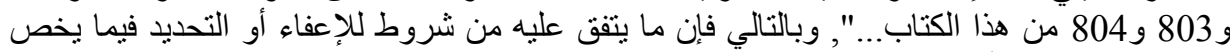

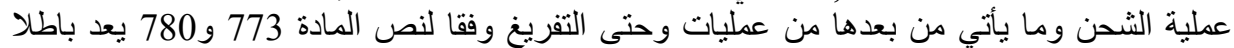
بطلانا مطلقا، لأن هذه الالتز امات تقع على عاتق الناقل و لا يجوز الاتفاق على ما يخالفها لتعلقها بالنظام

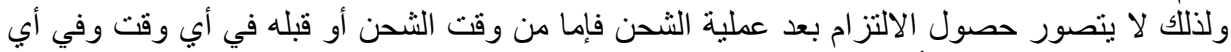

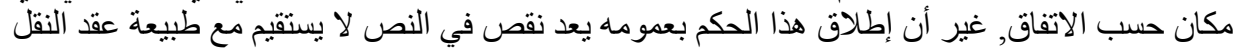

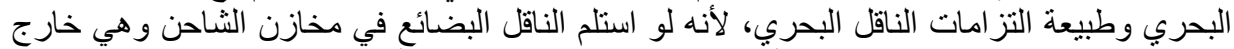

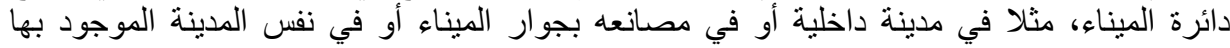




\section{بداية مسؤولية الناقل البحري عن البضاعة التي تسلمها في القانون الجزائري والاتفاقيات الدولية الئية}

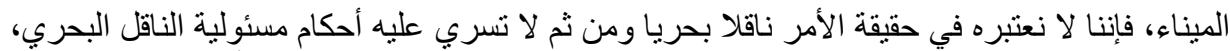

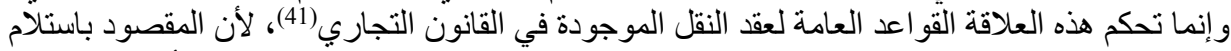

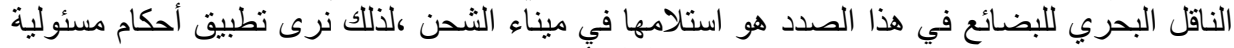

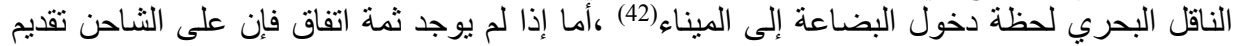

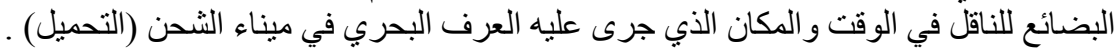

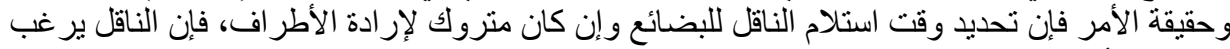

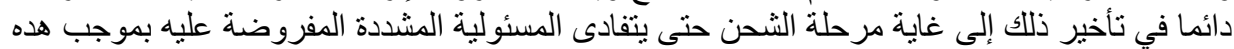

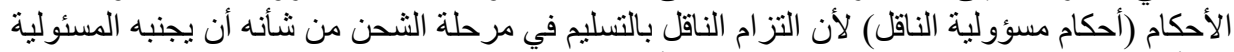

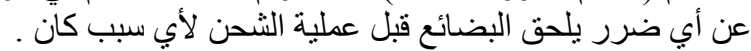

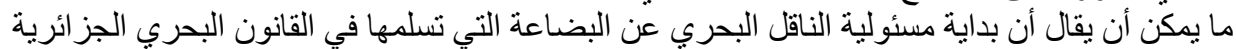

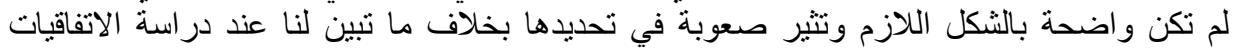

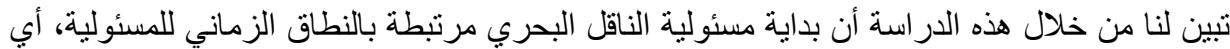

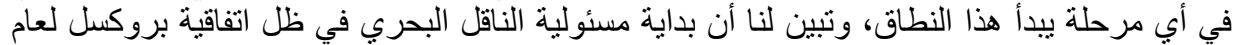

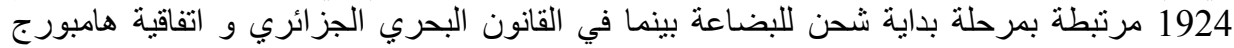

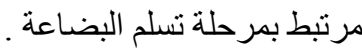

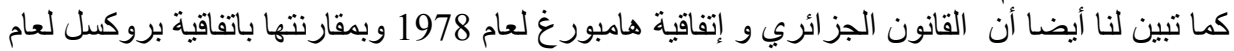

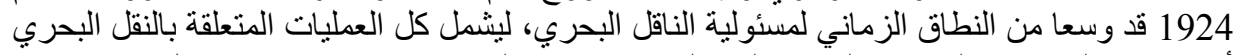

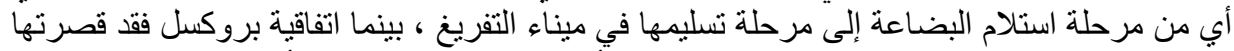

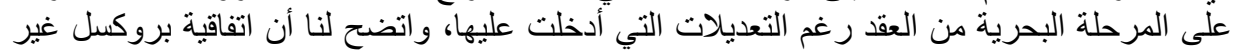

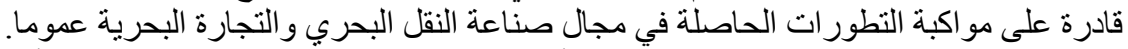

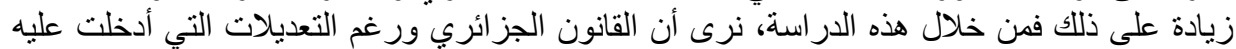

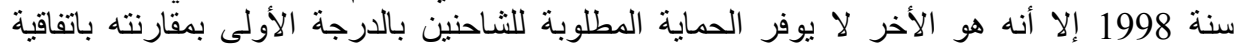

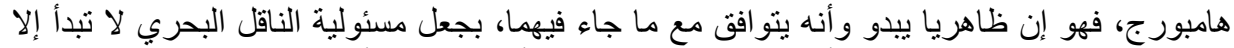

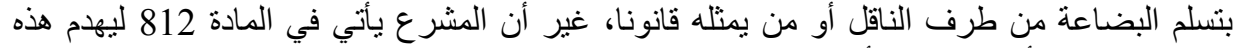

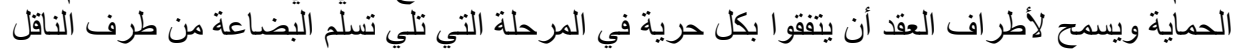

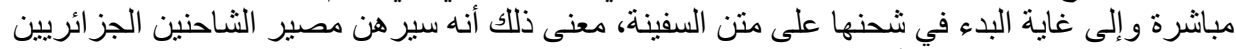

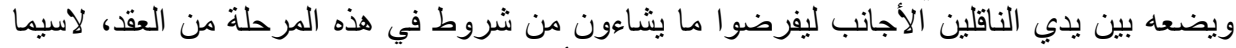

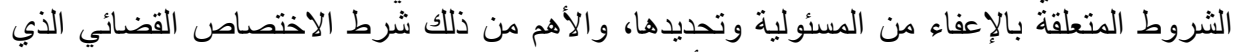

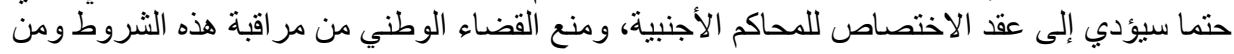

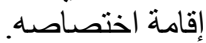

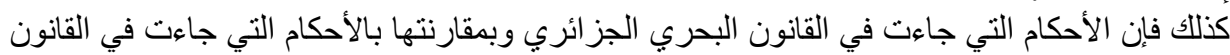

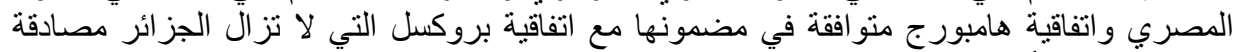

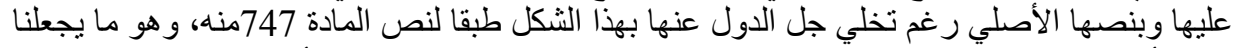

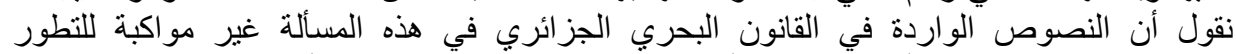

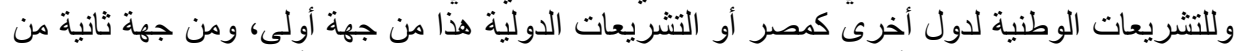

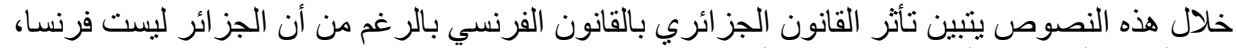

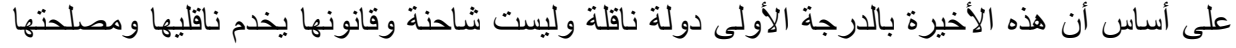

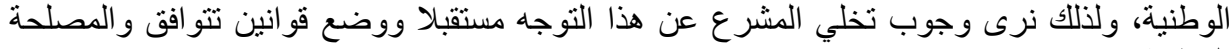


ما نصل إليه في النهاية وبمقارنة النصوص الأربعة محل الدراسة، تبين لنا جليا تفوق الأحكام التي

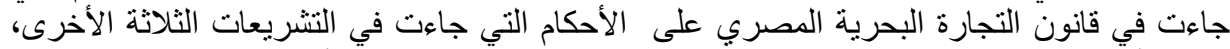

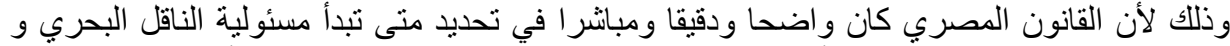

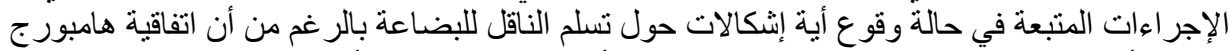

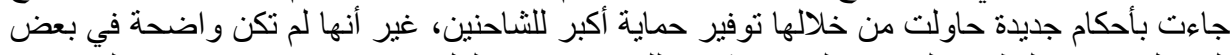

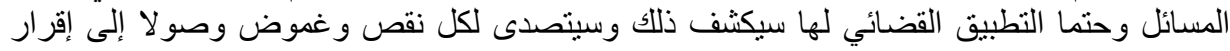

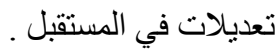

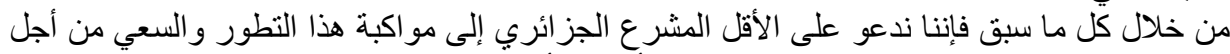

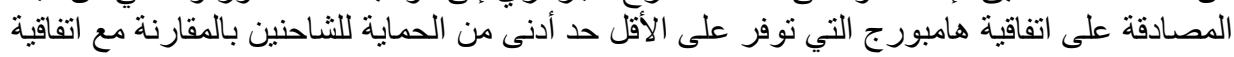

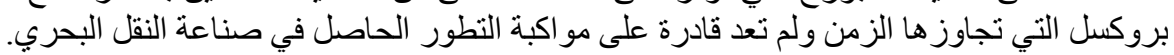

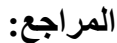

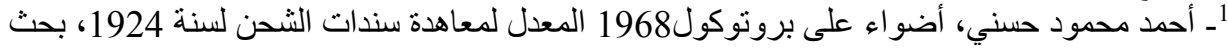

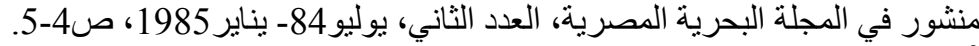

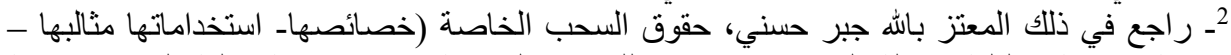

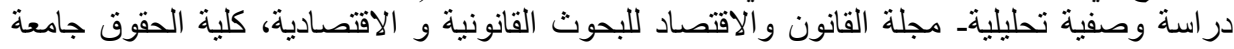

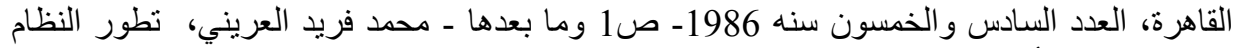

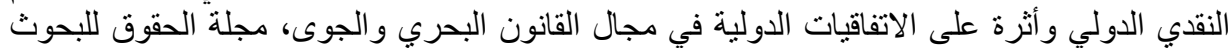

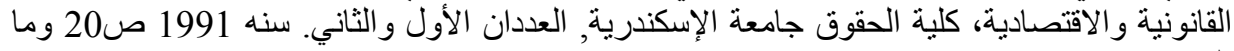
يليها.

3- صلاح المقدم، تنازع القوانين في سندات الثحن ومشارطات إيجار السفينةـ دراسة مقارنة في

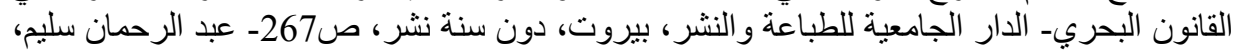

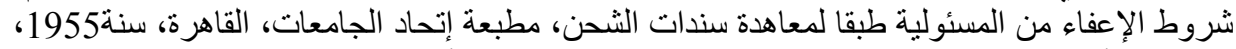
ص119- أحمد محمود حسني، النقل الدولي البحري للبضائع منشأة المعارف، الإسكندرية، طبعة ثانية، (78)

- Rodiére(R): La fin du sectionnement juridique du contrat de transport 4 maritime, DMF, 1966, p579. 5 - صلاح المقدم، المرجع السابق، 268.

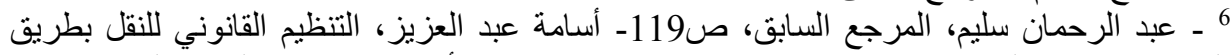

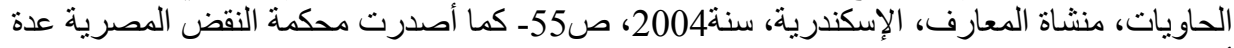

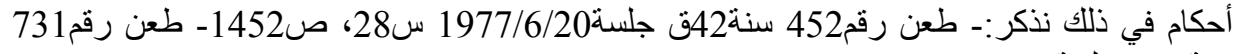

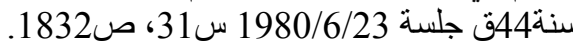

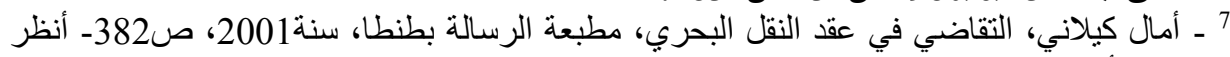

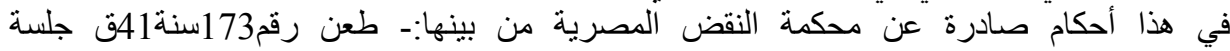

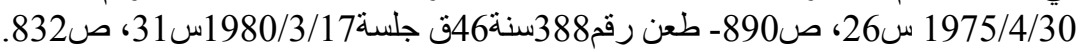

- Sauvage (F): La condition juridique des marchandises à tere avant 8 l'enbarqument et âpres déchargement, DMF, p136.

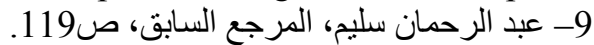
10- إبر اهيم مكي، دعوى المسؤولية على الناقل البحري، مطبعة الددني بالعباسية، القاهرة، سنة 1973،

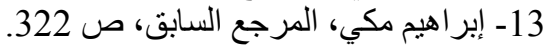




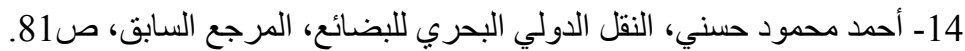

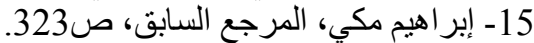

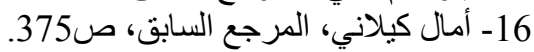

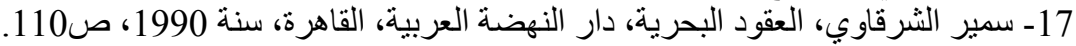
18- أسامة عبد العزيز، التنظيم القانوني للنقل بطريق الحارية الحاويات، منشاة المعارف، الإسكندرية،

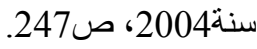

- Mercadal (B): Les problèmes juridiques de la conteneurisation du transport 19 maritime, DMF, 1982, p371.

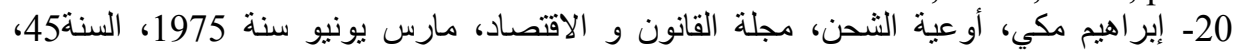

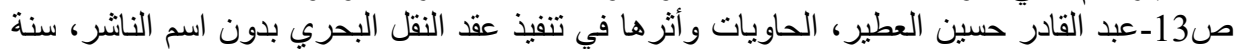

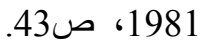

21- عبد القادر حسين العطير، اتفاقية الأمم المتحدة حول النقل الدولي متعدد الوسائل للبضائع لسنة

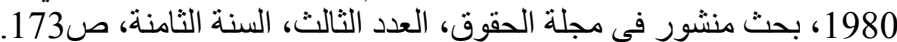

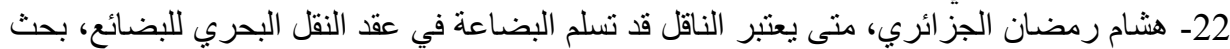

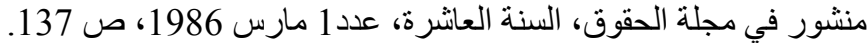

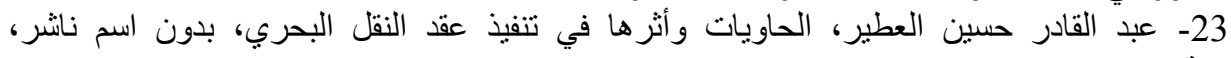

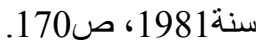

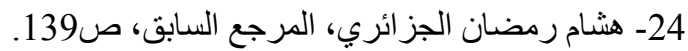

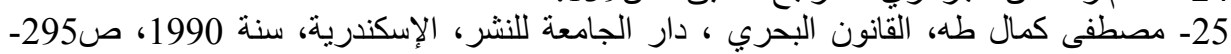
جلال وفاء محمدين، قانون التجارة البحرية، دار الجامعة الجديدة للنشر، الإسكندرية، سنة 1997

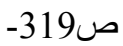

Ripert (G): La responsabilité du transporteur maritime d'après la loi du 2/4/1936, DMF, 1949, p6.

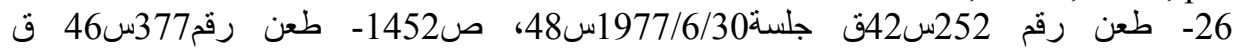

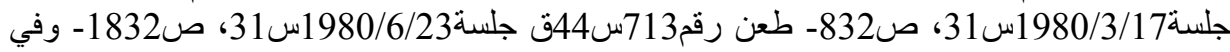

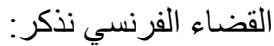

Trib.Marsseille,18/4/1950,DMF,1950,p198 - Trib. Bordeu 8/5/1951, DMF, 1951,393-Trib d'Alger, 8/12/1949, DMF, 1950, p510.

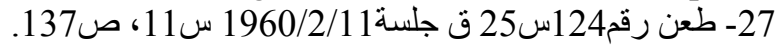

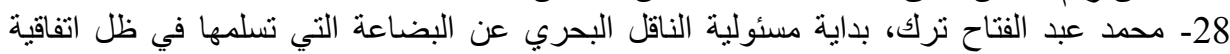

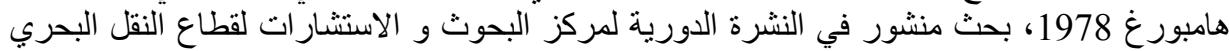

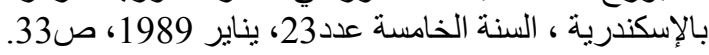
29- محمد بهجت عبد الله قايد، مسئولية الناقل البحري للبضائلة البائع في اتفاقية هامبورج، دار النهضة

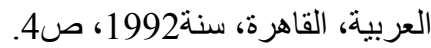

- Le Gendre(C): La Convention des nation unies sur le transport de 30 marchandises par mer, D.M.F, 1978, p390- Bokalli (V-E): La protection des chargeurs a travers les règles de Hambourg, DMF, 1997,246. 31- محمد بهجت عبد الله قايد، المرجع السابق، 35 .

32- الأمر رقم 86-68المؤرخ في 1976/10/23 المتضمن القانون البحري منشور بالجريدة الرسمية

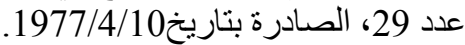


33- صادقت الجز ائر على اتفاقية بروكسل الخاصة بتوحيد بعض القو اعد المتعلقة بسندات الثحن لسنة

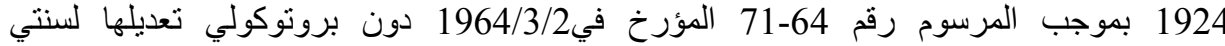

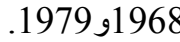

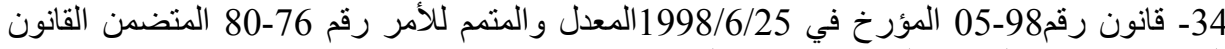

البحري، منشور بالجريدة الرسمية عدد

-Rodiére (R):Traité générale de droit maritime, Tome2, Dalloz, Paris, 35 $1968, \mathrm{p} 138$

36- كمال حمدي، مسؤولية الناقل البحري للبضائع في قانون التجارة البحرية رقم 8 لسنة 1990، منشأة

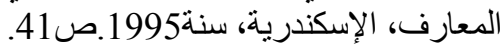

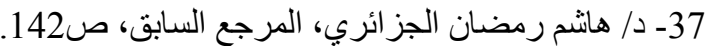

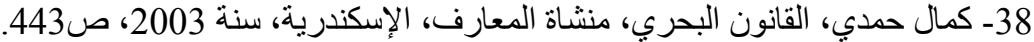

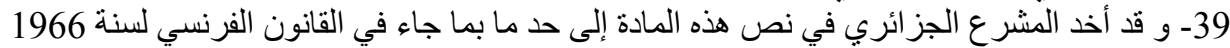
في مادته 27 التي نص فئنها على:

Le transporteur est responsable des pertes ou dommage subis par la marchandise depuis la prise en charge jusqu' à la livraison". وهو نفس الحكم الذي أخذت به معاهدة هامبور غ لسنة 1978ر اجع في ذلك :

Victor Emmanuel (B): La protection des chargeurs a travers les règles de Hambourg, DMF, 1997, p246.

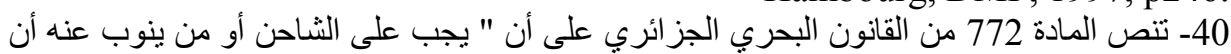

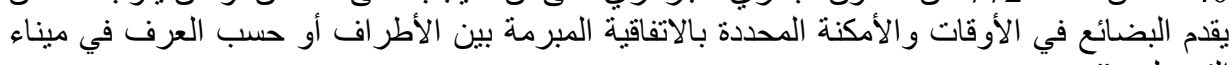

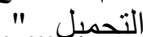
41- نص على هذه القواعد في المو اد من 35-55 من القانون التجاري الصادر في سنة 1975 بالأمر

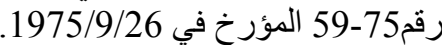
42- كمال حمدي، مسئولية الناقل البحري للبضائع، المرجع السابق، ص43. 